\title{
Is all hypoglycaemia treated as equal? An observational study of how the type of diabetes and treatment prescribed prior to admission influences quality of treatment of inpatient hypoglycaemia
}

\author{
Gregory C. Jones ${ }^{1}$ (D) Jansher Khan ${ }^{1} \cdot$ Christopher A. R. Sainsbury ${ }^{1}$
}

Received: 26 September 2016/ Accepted: 5 November 2016/Published online: 28 November 2016

(C) The Author(s) 2016. This article is published with open access at Springerlink.com

\begin{abstract}
Aims Inpatient hypoglycaemia is common and associated with adverse outcomes. There is often increased vigilance of hypoglycaemia in inpatients with type 1 diabetes (T1DM) compared to type 2 diabetes (T2DM). We aimed to investigate this apparent discrepancy, utilising the time to repeat (TTR) capillary blood glucose (CBG) measurement as a surrogate for engagement with guidelines stating that $\mathrm{CBG}$ should be rechecked following intervention within $15 \mathrm{~min}$ of an initial CBG of $<4 \mathrm{mmol} / \mathrm{L}$.

Methods This is an observational study of inpatient CBG data from 8 hospitals over a 7 -year period. A national diabetes registry allowed identification of individual's diagnosis and diabetes therapy. For each initial (index) CBG, the TTR for individuals with T2DM-on insulin or sulphonylurea-was compared with the TTR for individuals with T1DM, using a $t$ test for significance performed on $\log$ (TTR). The median TTR was plotted for each group per index CBG.

Results In total, 1480,335 CBG measurements were obtained. A total of 26,664 were $<4 \mathrm{mmol} / \mathrm{L}$. The TTR in T2DM individuals on sulphonylurea was significantly greater than in T1DM individuals where index CBG was $\geq 2.3 \mathrm{mmol} / \mathrm{L}$ (except index CBG $2.6 \mathrm{mmol} / \mathrm{L}$ ). For T2DM patients receiving insulin significance exists for index CBGs of $\geq 3.2 \mathrm{mmol} / \mathrm{L}$.
\end{abstract}

Managed by Antonio Secchi.

Gregory C. Jones

g.jones3@nhs.net

1 Diabetes Department, Gartnavel General Hospital, Glasgow G11 0YN, UK
Conclusions This analysis suggests that quality of care of hypoglycaemia varies according to diagnosis and medication. The group with the highest TTR (T2DM sulphonylurea treated) are possibly the clinical group in whom hypoglycaemia is most concerning. These data therefore suggest a need for education and raising awareness within the inpatient nursing staff.

Keywords Diabetes · Inpatient · Hypoglycaemia · Insulin · Sulphonylurea $\cdot$ Quality of care

\section{Background and aims}

Hypoglycaemia is an important co-morbidity in most patients with type 1 diabetes and many with type 2 diabetes and has potentially fatal consequences [1]. Fewer than $20 \%$ of patients with type 1 diabetes (T1DM) are free of hypoglycaemia in any year [2]. In patients with type 2 diabetes (T2DM), it has been reported that by 9 months of follow-up $7 \%$ of patients on recently initiated insulin or sulphonylurea treatment will have experienced severe hypoglycaemia (hypoglycaemia needing external assistance) [3]. Occurrence of severe hypoglycaemia has demonstrated to be associated with macrovascular events, adverse clinical outcomes and mortality in people with T1DM and T2DM $[4,5]$. As well as poor clinical outcomes hypoglycaemia is a complication greatly feared by patients and associated with significant psychological and social burdens $[6,7]$.

In hospitalised patients with diabetes, hypoglycaemia is common with a reported frequency of between 3.3 and 5.7\% [8-11]. In the UK National Diabetes Inpatient Audit, hypoglycaemia occurred in $45.3 \%$ of inpatients with T1DM and 31.8\% T2DM [12]. 
Sulphonylureas (SUs) pose a significant hypoglycaemic risk with a reported incidence of $19 \%$ of inpatients treated with SUs [13] and one-third of hypoglycaemic episodes attributed exclusively to SU therapy in an audit of 11 acute UK NHS trusts [14]. Although severity of hypoglycaemia was significantly greater with insulin therapy, the number of episodes of hypoglycaemia experienced was similar $[13,14]$.

Frequency and severity of hypoglycaemia have been associated with an increase in pre- and postdischarge mortality and length of admission [15-17]. Even in patients without diabetes, hypoglycaemia on hospital admission has been linked with a significant increase in inpatient mortality and bed occupancy $[18,19]$.

Patients experiencing hypoglycaemia (blood glucose $<4 \mathrm{mmol} / \mathrm{l}$ ) require prompt action with administration of rapid acting carbohydrate or glucagon followed by assessment of response to treatment by repeat blood glucose measurement. The Joint British Diabetes Societies inpatient care guidelines for the treatment of hypoglycaemia recommend that following treatment of hypoglycaemia capillary blood glucose (CBG) is repeated at between 10 and $15 \mathrm{~min}$ to ensure successful treatment [12]. This timescale for repeating CBG is also recommended by the American Diabetes Association for all episodes of hypoglycaemia occurring in patients with diabetes [20].

Compliance with guidelines for repeat testing following identification of hypoglycaemia is substandard. In a 5-year analysis of 8 acute hospitals in the UK, it was revealed that following recorded hypoglycaemia events $4.4 \%$ of patients had no repeat CBG. Of the repeated measurements, less than $10 \%$ had a TTR $<15$ min and the median TTR was $80 \mathrm{~min}$. As would seem instinctive, a proportional relationship was seen with TTR and severity of initial CBG values [21].

It has been our experience that in an inpatient setting there is often a high degree of awareness of hypoglycaemia in individuals with T1DM, but less awareness for those with T2DM.

We aimed to investigate for both the presence and scale of this apparent discrepancy in clinical vigilance by utilising the time to repeat (TTR) capillary blood glucose (CBG) measurement as a surrogate for engagement with extant clinical guidelines for hypoglycaemia - which in our institution state that $\mathrm{CBG}$ should be rechecked following intervention within $15 \mathrm{~min}$ where an initial $\mathrm{CBG}$ of $<4 \mathrm{mmol} / \mathrm{L}$ is identified.

\section{Patients and methods}

Inpatient CBG data were collected from 8 hospitals, comprising a variety of acute and general medical and surgical wards in district general and teaching hospitals, in the Greater Glasgow and Clyde Health Board over a period of 7 years to January 2016. CBG value, time of test, date of test and corresponding patient identifier were extracted from analysis of the Abbott Precision Webb system (Abbott, UK). Episodes of hypoglycaemia were identified as CBG of $<4 \mathrm{mmol} / \mathrm{l}$. Repeat CBG testing for the same patient identifier was then identified, and the time between the test was calculated to give the TTR. By merging the dataset with a national diabetes registry (Scottish Care Information Diabetes Collaboration System), it was possible to cross-reference patient identifiers and identify the individual's diagnosis of T1DM or T2DM.

Primary care prescribing information was available from the registry for all individuals with diabetes. Admissions were deemed to be associated with insulin or SU therapies if a prescription was identified during the 4 months prior to admission. During an admission, the time interval between each CBG measurement was calculated and analysed per initial (index) $\mathrm{CBG}$ value. For each index CBG, the TTR for those individuals with T2DM-insulin or SU treated-was compared with the TTR for those individuals with T1DM, using a t test performed on $\log (\mathrm{TTR})$ to test significance. The median TTR was plotted for each group per index CBG.

\section{Results}

A summary of results is represented in Table 1. In total, $1,480,335$ CBG measurements were obtained by the Abbott system in total. This comprised 406,690 values from 4304 individuals with T1DM, 484,067 values from 5164 individuals with T2DM on insulin therapy and 589,778 values from 13,015 individuals with T2DM on sulphonylureas (SU).

Table 1 Summary of diagnosis, therapy, number of CBG values and median TTR (IQR)

\begin{tabular}{|c|c|c|c|c|c|}
\hline $\begin{array}{l}\text { Diagnosis and } \\
\text { therapy }\end{array}$ & $\begin{array}{l}\text { Number of } \\
\text { individuals }\end{array}$ & $\begin{array}{l}\text { Number of CBG } \\
\text { values }\end{array}$ & $\begin{array}{l}\text { CBG values } \\
<4 \mathrm{mmol} / 1\end{array}$ & $\begin{array}{l}\text { Median (IQR) TTR } \\
\text { overall (min) }\end{array}$ & $\begin{array}{l}\text { Median (IQR) TTR for CBG } \\
1-3.9 \mathrm{mmol} / 1(\mathrm{~min})\end{array}$ \\
\hline T1DM & 4304 & 406,690 & 26,664 & $186(90-314)$ & $53(26-112)$ \\
\hline T2DM + Insulin & 5164 & 484,067 & 23,591 & 305 (159-552) & $64(30-147)$ \\
\hline $\mathrm{T} 2 \mathrm{DM}+\mathrm{SU}$ & 13,015 & 589,778 & 30,344 & $355(198-706)$ & $97(40-292)$ \\
\hline
\end{tabular}


Fig. 1 Median time to repeat of CBG by index $\mathrm{CBG}$ in $\mathrm{mmol} / \mathrm{l}$ for T1DM (green), insulintreated T2DM (black) and sulphonylurea-treated T2DM (purple) (colour figure online)

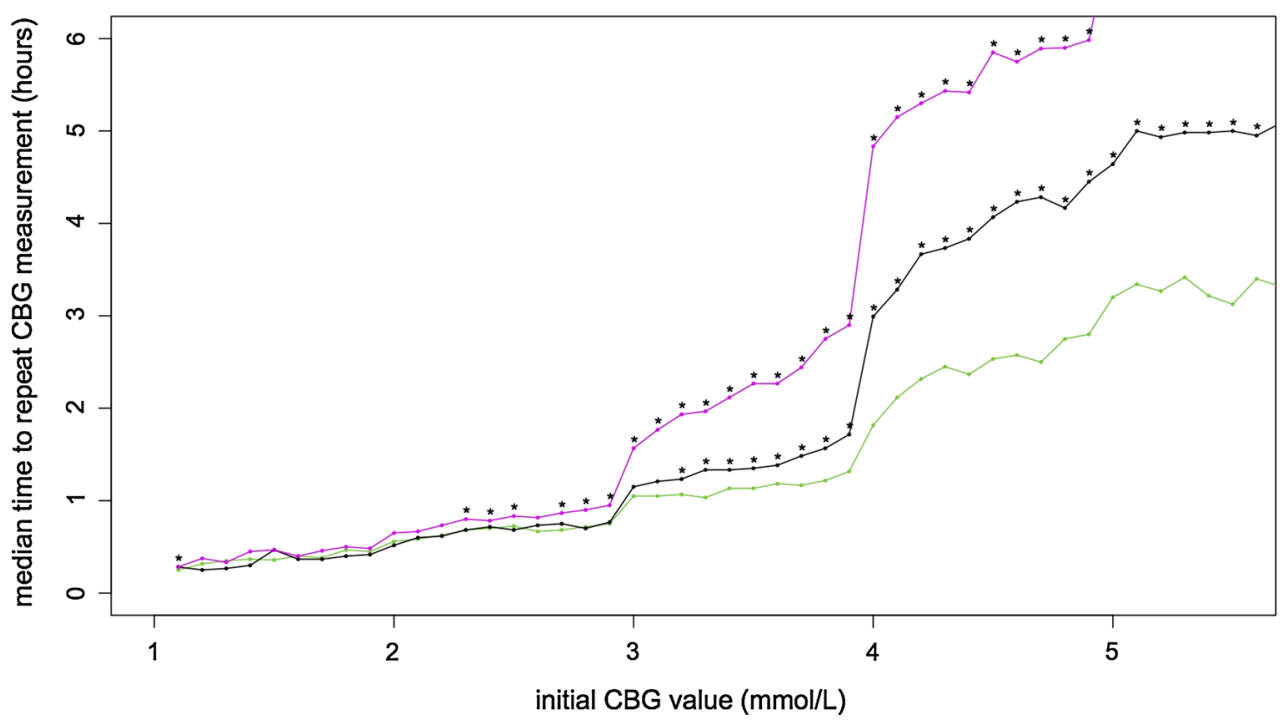

Of these readings, 26,664 were identified as being hypoglycaemic $(<4 \mathrm{mmol} / \mathrm{L})$ from individuals with T1DM, 23,591 from individuals with T2DM on insulin and 30,344 from individuals with T2DM on sulphonylurea therapy.

The overall median (IQR) TTR for all index CBG values (1-27.8 mmol/l) was: $186(90-314) \mathrm{min}$ in individuals with T1DM; 305 (159-552) min in patients with T2DM on insulin; and $355(198-706) \mathrm{min}$ in T2DM patients on SU.

The median (IQR) TTR for index CBGs in the range of 1-3.9 mmol/L was: $53(26-112) \mathrm{min}$ in individuals with T1DM; 64 (30-147) min in patients with T2DM on insulin; and 97 (40-292) $\mathrm{min}$ in T2DM patients on SU.

Figure 1 shows the relationship between the median TTR of CBG compared to index CBG level in patients with T1DM, T2DM treated with insulin and T2DM treated with a sulphonylurea with an indicator of significance where each T2DM group is compared with the T1DM group. The TTR in the subgroup of T2DM individuals on SU therapy is significantly greater than in T1DM individuals where the index $\mathrm{CBG}$ is $\geq 2.3 \mathrm{mmol} / \mathrm{L}$ (except index CBG $2.6 \mathrm{mmol} /$ $\mathrm{L})$. For the portion of $\mathrm{T} 2 \mathrm{DM}$ patients receiving insulin significance exists for index CBGs of $\geq 3.2 \mathrm{mmol} / \mathrm{L}$.

\section{Conclusion}

As has been reported previously the nationally agreed standard of repeating CBG following measured hypoglycaemia is not being met in the vast majority of patients [21]. Guidelines suggest identical action for hypoglycaemic CBGs regardless of clinical context. This analysis suggests that the level of adherence to guidance (which is a measure of quality of care) varies according to the underlying diagnosis and prescribed drugs. TTR decreases as the index CBG decreases as clinically expected, and a reduction in TTR is seen at those thresholds where the initial number of the $\mathrm{CBG}$ result decreases (e.g. 3.0 vs. 2.9)_as previously reported.

The difference in attitude towards noninsulin therapies was highlighted by the TOPDOC study. Investigation of confidence and approaches to delivery of diabetes care found that postgraduate medical trainees were less likely to alter oral therapy for diabetes management compared to insulin [22].

Rates of hypoglycaemia in T2DM patients on insulin are lower than for T1DM patients, although disparity reduces with advancement of disease [23]. Irrespective of cause hypoglycaemia is associated with a multitude of negative outcomes, and recent publications have identified comorbidity as potentially the most concerning contributor to hypoglycaemia [24], [25]. Patients admitted to hospital are likely to suffer from more advanced disease and comorbidities. They are also more likely to suffer from the risk factors associated with SU-induced hypoglycaemia, namely older age and reduced kidney function [13]. Furthermore, hypoglycaemia and SU therapy have both been implicated in direct cardiotoxicity, although causative evidence in this area is lacking [26].

Thus, although, understandably, there may be increased vigilance of hypoglycaemia in T1DM patients, the group with the highest TTR (T2DM SU treated) are possibly the clinical group in whom the risks associated with hypoglycaemia are greatest.

These data therefore suggest a need for education and raising awareness within the nursing staff within inpatient units. The benefit of such intervention in improving quality of inpatient hypoglycaemia care has been evidenced previously [21]. 


\section{Compliance with ethical standards}

Conflict of interest Authors have no conflicts of interest.

Ethical standard This study was conducted in accordance with the Declaration of Helsinki.

Human and animal rights All procedures followed were in accordance with the ethical standards of the responsible committee on human experimentation (institutional and national) and with the Helsinki Declaration of 1975, as revised in 2008 (5). This article does not contain any studies with human or animal subjects performed by the any of the authors.

Informed consent Informed consent was not required for this study.

Open Access This article is distributed under the terms of the Creative Commons Attribution 4.0 International License (http://crea tivecommons.org/licenses/by/4.0/), which permits unrestricted use, distribution, and reproduction in any medium, provided you give appropriate credit to the original author(s) and the source, provide a link to the Creative Commons license, and indicate if changes were made.

\section{References}

1. International Hypoglycaemia Study Group (2015) Minimizing hypoglycemia in diabetes. Diabetes Care 38:1583-1591

2. Giorda CB, Ozzello A, Gentile S et al (2015) Incidence and risk factors for severe and symptomatic hypoglycemia in type 1 diabetes. Results of the HYPOS-1 study. Acta Diabetol 52:845-853

3. UK Hypoglycaemia Study Group (2007) Risk of hypoglycaemia in types 1 and 2 diabetes: effects of treatment modalities and their duration. Diabetologia 50:1140-1147

4. Hanefeld M, Frier BM, Pistrosch F (2016) Hypoglycemia and cardiovascular Risk: Is There a Major Link? Diabetes Care 39(Suppl 2):S205-S209

5. Khunti K, Davies M, Majeed A et al (2015) Hypoglycemia and risk of cardiovascular disease and all-cause mortality in insulintreated people with type 1 and type 2 diabetes: a cohort study. Diabetes Care 38:316-322

6. Nicolucci A, Kovacs Burns K, Holt RIG et al (2013) Diabetes Attitudes, Wishes and Needs second study (DAWN2 ${ }^{\mathrm{TM}}$ ): crossnational benchmarking of diabetes-related psychosocial outcomes for people with diabetes. Diabet Med 30:767-777

7. Nicolucci A, Pintaudi B, Rossi MC et al (2015) The social burden of hypoglycemia in the elderly. Acta Diabetol 52:677-685

8. Swanson CM, Potter DJ, Kongable GL, Cook CB (2011) Update on inpatient glycemic control in hospitals in the United States. Endocr Pract 17:853-861

9. Jones GC, Casey H, Perry CG et al (2014) Trends in recorded capillary blood glucose and hypoglycaemia in hospitalised patients with diabetes. Diabetes Res Clin Pract 104:79-83

10. Bersoux S, Cook CB, Kongable GL, Shu J (2013) Trends in glycemic control over a 2-year period in 126 US hospitals. J Hosp Med 8:121-125
11. Kerry C, Mitchell S, Sharma S et al (2013) Diurnal temporal patterns of hypoglycaemia in hospitalized people with diabetes may reveal potentially correctable factors. Diabet Med 30:1403-1406

12. Health And Social Care (2016) National Diabetes Inpatient Audit 2015. In: National Diabetes Inpatient Audit. http://www.hscic. gov.uk/diabetesinpatientaudit. Accessed 16 Jun 2016

13. Deusenberry CM, Coley KC, Korytkowski MT, Donihi AC (2012) Hypoglycemia in hospitalized patients treated with sulfonylureas. Pharmacotherapy 32:613-617

14. Rajendran R, Kerry C, Rayman G, MaGIC study group (2014) Temporal patterns of hypoglycaemia and burden of sulfonylurearelated hypoglycaemia in UK hospitals: a retrospective multicentre audit of hospitalised patients with diabetes. BMJ Open 4:e005165

15. Turchin A, Matheny ME, Shubina M et al (2009) Hypoglycemia and clinical outcomes in patients with diabetes hospitalized in the general ward. Diabetes Care 32:1153-1157

16. Nirantharakumar K, Marshall T, Kennedy A et al (2012) Hypoglycaemia is associated with increased length of stay and mortality in people with diabetes who are hospitalized. Diabet Med 29:e445-e448

17. McEwan P, Larsen Thorsted B, Wolden M et al (2015) Healthcare resource implications of hypoglycemia-related hospital admissions and inpatient hypoglycemia: retrospective recordlinked cohort studies in England. BMJ Open Diabetes Res Care 3:e000057

18. Tan HK, Flanagan D (2013) The impact of hypoglycaemia on patients admitted to hospital with medical emergencies. Diabet Med 30:574-580

19. Tsujimoto T, Yamamoto-Honda R, Kajio H et al (2015) Prediction of 90-day mortality in patients without diabetes by severe hypoglycemia: blood glucose level as a novel marker of severity of underlying disease. Acta Diabetol 52:307-314

20. American Diabetes Association (2001) Living with diabetes. Hypoglycemia (low blood glucose). In: American Diabetes Association. http://www.diabetes.org/. Accessed 16 Jun 2016

21. Jones GC, Perry CG, Monaghan A et al (2015) Capillary blood glucose monitoring, inpatient hypoglycaemia and quality of care. Br J Diabetes 15:24-26

22. George JT, Warriner D, McGrane DJ et al (2011) Lack of confidence among trainee doctors in the management of diabetes: the Trainees Own Perception of Delivery of Care (TOPDOC) Diabetes Study. QJM 104:761-766

23. Donnelly LA, Morris AD, Frier BM et al (2005) Frequency and predictors of hypoglycaemia in Type 1 and insulin-treated Type 2 diabetes: a population-based study. Diabet Med 22:749-755

24. Braatvedt GD, Sykes AJ, Panossian Z, McNeill D (2014) The clinical course of patients with type 2 diabetes presenting to the hospital with sulfonylurea-induced hypoglycemia. Diabetes Technol Ther 16:661-666

25. Boucai L, Southern WN, Zonszein J (2011) Hypoglycemia-associated mortality is not drug-associated but linked to comorbidities. Am J Med 124:1028-1035

26. Hanefeld M, Duetting E, Bramlage P (2013) Cardiac implications of hypoglycaemia in patients with diabetes - a systematic review. Cardiovasc Diabetol 12:1-11 